\title{
Young children's spatial autonomy in their home environment and a forest setting
}

\section{Carie J. Green}

Abstract: Places assigned and places chosen have major implications for the lives of children. While the former are a result of children's subordinate position in an adult world, the latter are the essence of their agency. Beginning at a young age children seek out places to claim as their own. Places, real and imaginary, shape children and children shape them. This phenomenon of spatial autonomy is a formative, and extraordinary, part of their identity formation. While spatial autonomy has been casually referred to in the children's geographies literature, a theoretical framing of the concept is generally lacking. This article draws together findings from two research studies, which were conducted by the author, to further theorize the meaning of young children's (ages 3-6 years old) spatial autonomy in their home environment and a forest setting. Informed by a phenomenological framework, the studies used children's tours as a method. The findings reveal that spatial autonomy is an expression of children's independence enacted through symbolic play and hiding activities. The children sought out small places and high places where they could observe others while maintaining autonomy. Additionally, spatial autonomy is relational, negotiated within adult imposed-regulations and influenced by peers, siblings and other more-than-human elements in their environments. By claiming just-out-of reach places, the children collectively and independently established their own rules and a sense of control. The achievement of spatial autonomy plays an important role in young children's identity formation, boasting their self-confidence as they develop a sense of self with places in all the various environments of their lives.

Keywords: young children, sense of place, spatial autonomy, symbolic play, hiding. 


\section{Introduction}

Spaces and places do not only influence children, but children also influence and shape places. Indeed, from a very young age, children express a desire to create or claim their own places in the world (Green, 2011; 2013). This constructing and claiming of place, is an important part of children's enactment of spatial autonomy, and plays a significant role in children's discovery of their sense of self (Cobb, 1977; Green, 2013; Proshansky $\&$ Fabian, 1987). While the concept of "spatial autonomy" has been casually referred to in contemporary children's geography literature (Bromley \& Mackie, 2009; Freeman, 2010; Lehman-Frisch, Authier \& Dufaux, 2012; Tomanović \& Petrović, 2010; Travlou, Owens, Thompson \& Maxwell, 2008; Wilson, Houmøller \& Bernays, 2012), it has not been specifically theorized or defined. In other words it appears to be a somewhat taken-for-granted concept, and has often been used simultaneously with "spatial negotiation" and "spatial practices." The purpose of this paper is to further theory on the meaning of young children's spatial autonomy and how it is enacted in their home environments and in a forest setting. The decision to compare and distinguish children's experiences in these two settings was taken because they are shaped by different social-relational dynamics; namely, the home environment is largely structured by parents, and the forest, generally speaking, is less structured and restrictive. This paper explores what children's spatial autonomy can include, mean, and how it is enacted by two groups of preschool-aged children from two different regions of the United States.

\section{Conceptualizing Children's Spatial Autonomy}

The concept of spatial autonomy is drawn from older research and related fields such as environmental psychology and is generally used to refer to children exercising their own agency in particular places and with others (human and more-than-human beings and objects) within these spaces (Chawla, 1992; Hart, 1979; Proshansky \& Fabian, 1987). Chawla (1992) argued that from the time that children first become mobile, they seek to achieve spatial autonomy by making their own place in the world and exercising agency within their places. From crawling into a laundry basket, to building forts with blankets, to exploring a nearby waterway, children strive to find their own sense of place in their environment. This, Proshansky and Fabian (1987) argued, plays an important role in children's identity formation. Others have discussed how children's spatial autonomy is negotiated and renegotiated within adult-imposed boundaries, situated in both time 
and space and within particular social and cultural contexts (Punch, 2002). The word "spatial" is defined as "relating to, occupying, or having the character of space" (Merriam-Webster, 2018). "Autonomy" refers to "self-directing freedom" or "the state of self governing" (Merriam-Webster, 2018). So putting these two words together, Spatial Autonomy, might imply a self-directed space, or space where an individual seeks freedom and independence.

\section{Place, child embodiment, and situated agency}

Drawing from environmental psychology literature, "place" can be conceptualized as an "environmental locus in and through which individual or group actions, experiences, intentions, and meanings are drawn together spatially" (Seamon, 2014, p. 11). Places can range in scale from small to large, from a space under a table to a forest setting, or a city (Seamon, 2014). Seamon (2014) asserts a phenomenological understanding of place in that "place is not the physical environment separate from people associated with it, but rather, the indivisible, normally unnoticed phenomenon of person-or-people-experiencing-place" (p. 11). This understanding of place framed the qualitative approaches taken in the research presented in this article.

Furthermore, in seeking to understand children's spatial autonomy, we must also consider the meanings that young children themselves assign to a place. Meanings, however, should be recognized as fluid rather than stagnant; what a place means to one individual might mean something quite different for another. As well, the meaning a child assigns towards a place shifts over time and with growth and changes in physical, cognitive, and socioemotional understandings. As Manzo (2003) argued, "people's relationships to places are an ever-changing, dynamic phenomenon, and as such, they can be a conscious process in which people are active shapers of their lives" (p. 47).

In considering a phenomenological perspective of place, it is important to recognize the embodied child. The embodied experiences of children are unique and distinguished from those of adults, both physically and psychologically (James, 2000). A child's embodied experiences are informed by their "situated agency," that is, where a person is at a particular time and a particular place (James, 2000). Agency is related to a child's will to act either independently or collectively with others. Children exist within both an adult world and within their own constructed childhood culture (Corsaro, 2015). Young children, however, have little to no control, over the environ- 
ments or settings in which they are exposed. In other words, they are born into certain family structures, located within specific geographical locations, and embedded within particular cultural values and traditions (Punch, 2002). For instance, Punch (2002) found that children's spatial autonomy in rural parts of Bolivia is negotiated between work and play. Particularly because of work demands "the time that adults allow children to dedicate to play is limited, [therefore] children devise ways of extending that time by combining play with work" (p. 59). Among children from urban societies access to spaces outside the home is often more limited because of parental concerns for safety (Valentine, 2004).

To this extent, children's spatial autonomy is also constrained by adult permissions and restrictions. As Valentine (2004) writes in regards to public spaces, children's spatial ranges are a negotiation of power between children, and between children and adults. Adults set the boundaries of where a child can and should go (Hart, 1979), and children's experiences of places, depending upon the amount of freedom provided by adults, are more or less influenced and shaped by adults. Thus, situated agency informs a child's spatial autonomy, that is, how they relate with and make meaning of place.

\section{Research related to children's spatial autonomy}

Hart's (1979) seminal study of Children's Experiences of Place in New England, U.S., revealed children's perspectives of their surrounding outdoor environment. His findings revealed that children lay claim to forts, hiding places, and other places of solitude and retreat where they can "look upon the world from a place of [their] own" (Hart, 1979, p. 211). Others have investigated children's experiences of (outdoor) forts, huts, and secret hideouts during the middle childhood years. (Kjørholt, 2008; Kylin, 2003; Sobel, 2002). Kjørholt (2008) argued that "often these places are seen as secret places, reflecting a separate children's culture developed within a particular microcosm" (p. 261). Similarly, Sobel (2002) noted that such places provide children with the opportunity to control and manipulate their environment and provide a space separate from adults. Although there have been a substantial number of studies that have considered children's fort-making activities during the middle childhood years, none have interrogated fort-making during the preschool years and how it relates to children's spatial autonomy.

Additionally, studies have looked at preschool children's place interactions in school and day care settings (Lowry, 1993; Skånfors, Löfdahl \& 
Hägglund, 2009). These studies show that young children are attracted to indoor places of secrecy and places that can be used for the purposes of exclusive and/or selective play (Lowry, 1993; Skånfors et al., 2009). Skånfors et al. (2009) identified two withdrawal strategies used by preschool children: "making oneself inaccessible" and "creating and protecting shared hidden spaces" (p. 105). Such strategies, although occurring in a preschool setting, reveal young children's enactment of spatial autonomy. There is a need to further theorize young children's spatial autonomy, what it means and what it can include, in children's home environments and in a forest setting. This article draws together findings from two research studies that I conducted to elucidate the meaning of young children's spatial autonomy.

\section{Researching Young Children's Spatial Autonomy in their Home and in a Forest Setting}

The two research studies involved preschool children (ages 3-6 years old) from two different locations. The first study focused on the locations, experiences, and characteristics of young children's special places in their home setting, both indoors and outdoors. It was conducted in 2010 and involved 31 preschool children from a small Rocky Mountain community in the western United States (Green, 2013; Green, 2015). The second study was also comprised of 31 preschool children, who were attending a university early childhood education program; this study took place in a forest near a city in the interior of Alaska during the summer of 2015. Its aim was to investigate participatory methods for engaging young children as active researchers (Green, 2015b; Green, 2017a). The study also examined how children's interactions in a forest shaped their environmental identity development (Green, 2016b). While the study was not specifically directed at investigating children's connections with particular places, the findings that emerged furthered our understanding of children's spatial autonomy in a natural (forest) setting.

The two studies were conducted within participatory and phenomenological frameworks, and focused on the essence of children's lived experiences of being in particular places with particular settings (Schwandt, 2015). Phenomenological meanings are socially and independently constructed and based on both an individual's past and present experiences. Both studies utilized participatory methods of research with children that honor children's voices and perspectives (Barratt Hacking, Cutter-MacKenzie \& Barratt, 2013; Green, 2015), including child-led tours, children's artwork and model making, and book discussions. However, the findings presented in 
this paper will primarily be drawn from the child-led tours. Child-led tours are effective for tapping into phenomenological meanings derived from an individual's "perception (hearing, seeing, etc.)" and "experiences of bodily action" (Schwandt, 2015, p. 234).

The child-led tours were structured slightly differently in each study. In the special place study, the children were invited to lead a "place tour" in their home environment in which they showed and told me about all of the places that were important to them (Green, 2012). In the forest study, the children were invited to participate in sensory tours (Green, 2016a). This method diverged from the place tour by inviting children to wear cameras while they explored and played in their environment. The wearable camera authentically captured what children "see, hear, say, and touch in their environments" without the interference of an adult (Green, 2016a, p. 282). Although findings from both studies provided information about children's spatial autonomy, the sensory tour method used in the forest study rendered visible more detail of children's play activities because it captured the children while they were authentically engaged in the act. Whereas, during the special place tours the children were invited to tell me what they typically do in their places, without actually being engaged in doing it.

The videos of the children's place tours and sensory tours were transcribed into text files; the text included not only the children's verbal expressions but also a detailed description of the setting, the children's activities, and their non-verbal expressions. The transcriptions were read several times to gain a sense of the material, as a preliminary stage of qualitative analysis (Bogdan \& Biklin, 2007). During the second stage of analysis the data was coded and analyzed according to themes representative of the children's place and environmental connections. While the data from the two studies generated a wealth of information on children's preferences and experiences of places as well as their environmental identity formation, for the purposes of this article I have considered the qualitative themes that emerged from both studies in order to theorize further about children's spatial autonomy. Specifically, findings from both the studies will be used to explore what the concept of spatial autonomy can include, mean, and how it is enacted by young children in their home environment and in a forest setting. Thus, the findings presented in this paper should not be considered a comprehensive account of the findings from the two studies; rather some of the findings were purposively selected to provide illustrative examples of children's enactment of spatial autonomy in two distinct contexts. The findings presented below include transcribed portions of the children's place 
and sensory tours. The children's tours are indented in the text and quotes from the children's verbal expressions are italicized to draw attention to their voices and perspectives.

\section{Young Children's Enactment of Spatial Autonomy}

The findings from the research supported and went beyond past studies, revealing that young children achieve spatial autonomy through multiple ways, including through play (constructive and symbolic), hiding, and retreating to spaces that provide them with a personal sense of comfort and security. The children sought out small places (too small for an adult), and high places where they could look out over peers and adults. They also pointed to a connection with places that had been personalized in some way, using either images[objects] associated with characters from popular culture (e.g., Santa Claus and Hello Kitty), which in turn reflected wider cultural values and beliefs Furthermore, while some achieved their spatial autonomy independently, many discovered it with others (peers and siblings) through play and creative innovation.

\section{Gaining independence through symbolic play}

Across both studies, children's spatial autonomy was demonstrated through symbolic play in certain spaces. Symbolic play occurs when children use their imagination or role-playing to transform themselves or objects into play props (e.g., a leaf becomes a cookie) (Smilansky \& Shefta, 1990). Following their play themes, the children transformed places, people, and the objects within these spaces. Examples of the indoor and outdoor places claimed by the children as well as their symbolic play activities are represented in Table 1 .

Table 1: Examples of the indoor and outdoor places claimed by the children

\begin{tabular}{|l|l|}
\hline Places in/near Home & Play Scheme \\
\hline Behind a couch & $\begin{array}{l}\text { Playing tea party with friends and dolls } \\
\text { "Play with my babies" }\end{array}$ \\
\hline In a closet & $\begin{array}{l}\text { Pretending to be a witch: "Sometimes I turn some stuff into } \\
\text { magic, sometimes I play with magic, sometimes I play witch, } \\
\text { and sometimes I play with people." }\end{array}$ \\
\hline Under a table & $\begin{array}{l}\text { "Playing babies" } \\
\text { "Play monster" }\end{array}$ \\
\hline Behind living-room chair & Playing "campout" \\
\hline In/under bed & "Playing with babies and bears" \\
\hline
\end{tabular}




\begin{tabular}{|c|c|}
\hline Under blankets & Playing with toys and stuffed animals \\
\hline Blanket Tents (indoor) & $\begin{array}{l}\text { Pretending in an ocean } \\
\text { Playing with dolls and stuffed animals } \\
\text { "Have a fire pit so the fire would block my tent so no one } \\
\text { would get through it." } \\
\text { "Baby games" }\end{array}$ \\
\hline Under trampoline & Playing tea party \\
\hline In sandbox & Building castles \\
\hline In a bush house & Hiding with friends, rocks became furniture \\
\hline On a hill & $\begin{array}{l}\text { Constructing bombs and magic potions to "thwart off the } \\
\text { enemy" }\end{array}$ \\
\hline Rocks & "Looking for diamonds and rubies" \\
\hline Places in a Forest & Play Scheme \\
\hline A spruce tree (house) & Making tea or food with leaves and birch sap. \\
\hline $\begin{array}{l}\text { A "Princess Castle" (under } \\
\text { trees) }\end{array}$ & Playing "princess superhero," with super powers \\
\hline A Castle (under trees) & $\begin{array}{l}\text { Hello Kitty's birthday } \\
\text { Wild rosebushes are strawberries for kitty's birthday cake }\end{array}$ \\
\hline "Monster castle" (fallen tree) & Fighting off monsters and bad guys \\
\hline A tree $\operatorname{limb}$ & Moving a "robot arm" \\
\hline In trees & $\begin{array}{l}\text { Pretending to be Santa Claus: "It's Christmas time!" "Ho, ho, } \\
\text { Merry Christmas! Pretending to deliver presents by picking } \\
\text { up forest foliage }\end{array}$ \\
\hline In the forest & $\begin{array}{l}\text { Pretending to be Arial in Little Mermaid "There's a sea } \\
\text { monster!" } \\
\text { Breaking branches from the trees, two boys proclaim that } \\
\text { Wolverine is the strongest }\end{array}$ \\
\hline On a tree branch & $\begin{array}{l}\text { Riding on a spaceship to "California" } \\
\text { Swimming in a submarine in the sea }\end{array}$ \\
\hline
\end{tabular}

In the special place study, the children indicated a preference for playing in small-personalized spaces inside their home environment. They would bring certain toys to these spaces to enhance their play themes (e.g.,dolls and stuffed animals). For example, Emily shared her special place behind the couch in the living room. During her tour, she took me behind the couch and showed me a little round table with two tiny chairs, a purple tray, a pink teapot, and two tiny mugs. She told me how she used this space to host tea parties for her friends and dolls. Although it was in the family's living room, the space was personalized in that it contained her playthings.

The outdoor play spaces selected by the children were more open-ended and abstract. Specifically, the spaces were not as small or confined. Perhaps, this is because parents or other adults do not necessarily control the natural environment, as they do in the family home. Outdoors, the children imagined places using existing physical elements (e.g., trees, fallen branch- 
es). Instead of using play toys that represented certain things, the children transformed found and natural objects into props for their play. A few took on the role of certain characters (e.g., Arial from the Little Mermaid; Santa Claus; and Spiderman). The scene below, captured during Jade's sensory tour, demonstrates how she achieved spatial autonomy through the children's symbolic play. Jade claimed a "princess castle" with her friend Eleanor among four tall trees that formed a circular dome in the forest:

"We are in the castle," Jade said as she looked up towards the sky. "You gotta be quiet. Shh..." Eleanor said putting her finger next to her lips.

"This is a castle," Jade repeated.

"I know. The princesses... this is our castle," Eleanor agreed, "Let's stay at our castle and have a nice warm snack."

Eleanor gave Jade a tiny crumbled leaf, after blowing on it.

"I wanna eat that one," Jade indicated, pointing to a leaf on a branch.

"Okay we've gotta snack. We've got cookies!" Eleanor said, looking up at the trees.

"Okay, mmm..." said Jade.

"A castle..." Eleanor said.

"Do we have cherries?" Jade asked, grabbing a flower from the nearby rosebush.

"Princess magic. These are magic cherries, we have to put on our sprinkles," Eleanor sprinkled crumbled leafs on top of the "cookies."

In this example, Jade and Eleanor achieved spatial autonomy together by imagining a shared space in the forest where they could be princesses. In their princess castle, the children delighted in magical sweets that they harvested and gathered nearby. In their princess castle anything was possible, the children transformed their environment to fit their desires.

\section{Claiming forts, castles, and houses}

Notably, like children in middle childhood (Kjørholt, 2008; Kylin, 2003; Sobel, 2002), the young children in both studies claimed forts, castles, and houses. As shown in Table 1, some children constructed blanket tents inside their homes. Others claimed forts and monster castles outdoors. These types of places, particularly those found in the forest, were not constructed, rather they were inspired by environmental features (the arc of leaning tree branches, the rise of a fallen tree trunk, and other logs of different sorts that distinguished a particular area in the forest). There were also 
notable trends between the genders. Girls primarily claimed "houses" and "homes" as places to make food or participate in other domestic-like activities. "Forts" were primarily claimed by the boys and served various play and utilitarian purposes (e.g.., staying dry from the rain). "Castles," depending on the type, were discovered by both genders. A group of girls found "princess castles" where they played "princess super hero" and one boy became infatuated with a "monster castle" where he battled with monsters and bad guys.

Heather came upon her "house," a tall black spruce tree in the forest, where a group of girls had gathered. While the other girls went to play somewhere else, Heather liked the idea of a house and shared it with Priscilla. The girls soon gathered leaves and brought them to the house to make tea, sticking them on the sap covered trunk. However, after some time Priscilla lost interest in the house and told Heather that she wanted to go explore somewhere else. Heather reluctantly went along with Priscilla, but after some time exploring she invited Priscilla to return to her "home". Depicted below is a scene from Heather's sensory tour:

"If you get hungry in pretend, then I will lead you back to the house," Heather suggested to Priscilla.

"What did you say?" asked Priscilla.

Heather explained, "If you are wanting to get back to the house, I can lead you. When you want to go back to the house. I'll lead you."

Priscilla appeared uninterested, but Heather insisted, "Hmm... I want to go back home. Follow me and we'll be back there."

Heather started back towards her house, her pace quickened and she began to softly hum as she neared her "home." The video shows how Heather went away from her house three additional times to explore with Priscilla. Yet after each exploration she eagerly returned to her spruce tree. Heather shared her desire to stay, "I don't want to go. I want to be in the house."

"Don't you know you're supposed to go?" Priscilla persisted.

"Yes, I like it here. And I explored around and realized this could be... well somebody else finded that out and then I finded that out and then I wanted to use this as my house and I explored the farthest place so we'd be alive. For all the food and drinks. So that is exploring..."

In this example, Priscilla and Heather seem to have formed a different relationship to their "house." Heather was more attached to the idea of a house than Priscilla. Heather retreated back to the house time and time again 
while Priscilla said that she would rather explore elsewhere. Both behaviors denote a form of children's spatial autonomy, that is, children's shared and individual connection to place. Neither was wrong or right; rather their spatial autonomy was just of a different nature.

Additionally, Priscilla's statement, "don't you know we're supposed to go" suggests that she is drawing on some authority, maybe the teacher's, who had perhaps asked them to exercise their spatial autonomy through exploration. Priscilla seemed convinced that staying at the house was not something that they were supposed to do. In this way, the two girls negotiated what it means to explore, and how to exercise spatial autonomy within adult rules and expectations. Heather's final statement defends her goal of staying at the house, while pointing out that she had sufficiently engaged in the exploration: "And I explored around and... the farthest places... so that is exploring."

\section{Negotiating adult-rules through hiding}

Hiding, a form of play, was the second most prevalent activity in the special place study. Children hid in closets, under blankets, under tables, behind curtains, and in between furniture. The children enjoyed the social aspect of hiding; during home visits all of the children appointed me as seeker in their game of hide and seek.

Four-year-old Sara and three-year-old Caleb, siblings, hid in 18 different places during their special place tour. When I arrived at their home the children were already hiding under their kitchen table. Next, Sara hid in a little corner behind the couch, and Caleb hid in the cabinet under the stairs. They hid in their brother's room (a place typically forbidden by their parents), in a toy chest, in the dark bathroom with flashlights, in a closet, under their beds - Sara slid under hers first and Caleb mimicked Sara in sliding under his. Once spotted the children proceeded to the next places: behind a white plastic shelf, behind a chest of drawers, behind their bedroom door, in another closet, behind a bathroom door, under the blankets in their parents' bed, behind window curtains in the living room, behind the couch again, and between the refrigerator and the wall in the kitchen. I asked the children why they liked to hide. Sara answered, "Because...when Laura (her friend) comes, we hide!" Caleb added, "Because we want to!" By choosing where, when, and how long to hide Sara and Caleb exhibited control over their environment. Additionally, the children challenged parental rules during their hiding game by accessing places that were typically off 
limits. Their mother unlocked their brother's room for the children to access and although the cabinet under the stairs had previously been banned the children climbed inside it anyways.

Similarly, Tesa led me to a "forbidden place" during her hiding game. She took me to her parent's walk-in closet, a place that I would not likely visit on any other occasion. The transcript from Tesa's place tour reveals our interaction:

"How do you like this?" Tesa asked, pointing to one of her mother's dresses.

I smiled and nodded my head in agreement, feeling apprehensive about being in her parents' closet.

"I'll be right back," Tesa said, sliding quietly to the other side of the hanging dresses.

"Can you see me?" she asked, "This is one of my special places. Can you see my toes? Can you see me now?"

Playing along, I answered, "No, I can't see you. I can just hear you." "I'm playing hide and seek with you," she stated, pushing through some of the shirts. "Let me get out of the clothes," she said. "Watch, I'll show you how I got through, I put all the clothes in a pile, and look, then I snuck through, then I'm trying to find the dress, there's no dress. Then I pushed through."

The children in the special place study gained a sense of spatial autonomy through claiming hiding places in their home environment. Whether it was sneaking around in a closet, hiding under covers, or surprising me in choosing when and where they wanted to hide, the children created their own rules of their hide and seek games. Corsaro (2015) argued that one of the most prominent features of childhood is children's "persistent attempts to gain control of their lives" (p. 134). Through hiding, the children created their own childhood culture, which gave them a sense of autonomy in their homes, a place largely controlled by adults.

In the forest research study, children's hiding activities were not readily noted. Perhaps, this was because one of the parameters set by the teachers during the children's forest play was that they must be visible to a teacher at all times. Thus, hiding had been indirectly restricted. However, another way that spatial autonomy was exhibited was through claiming high places where they were unreachable. 
Some children also sought out high, almost unreachable, places. "Look at us! Look at us! Teacher! Teacher! Teacher! Teacher!" four-year-old Sergo shouted at his teacher from up high above the branches of a dead spruce tree. The main trunk of the tree, with its brittle and bare branches, rose at an angle nearly 8 feet above the ground. "I am climbing right here." Sergo explained.

On more than one occasion, four-year-old Sergo climbed up the skinny trunk of a fallen birch tree in the forest. Calling out to his teacher and peers to take notice, Sergo ascended the tree with confidence. Sergo was the leader of most of the climbing adventures in the forest, with other children following. Scaling up the tree, in turn, demonstrated Sergo's sense of spatial autonomy, his desire to be above his teacher and peers. Corsaro (2015) argued that children have a preference for places "where they are, in a very real sense bigger" (p. 135). Not only did climbing the tree provide Sergo with a heightened view of the world, he also felt strong on the tree branches, engaging in battle with the monsters and bad guys. He called the fallen tree his "dinosaur castle" and the following scene captured during Sergo's sensory tour unfolds his engagement in battle:

Sergo moved the dead branches up and down, holding them to keep steady.

"This one here, Teacher, this here is monster. This here is monster. And it goes rahh!!! RAH!!!! RAH!!! RAH!!! RAH!!! RAH!!!” Sergo explained to his teacher, moving the two branches apart and back together, shaking them at each other.

"What did you make?" his teacher asked.

"This is dinosaur," Sergo explained, pointing to one of the branches.

"Dinosaur?" His teacher asked.

"Yeah," Sergo said, "This one is more like people and this one is going Rah! Rah!"

Sergo trimmed the small limbs off the larger branch. He showed how the two sticks fight (the dinosaur and people). A "people" stick broke off and fell to the ground.

"Uh-oh. That's okay. Rah! Rah!" Sergo roared, shaking the "monster" stick around.

"This is dinosaur. Right there, right there, and right there. This all dinosaur." Sergo pointed to all of the branches ascending out of the fallen tree.

"This is dinosaur castle. This is dinosaur castle." Sergo explained. 
Sergo's dinosaur castle provided him with a strong sense of place in the forest environment. His play scheme continued visit after visit, with Sergo seeking to gain new heights on fallen branches to battle dinosaurs, monsters, and bad guys. Through claiming a dinosaur castle, Sergo constructed an identity where he felt strong and confident. He gained a sense of spatial autonomy, which also seemed to enhance his self-esteem (Laufer \&Wolfe, 1977).

In the special place study, children often claimed small places, too small for adults (e.g., in closets, under beds, under blankets, in cupboards, and in places between furniture). Although I am not a large person, I was initially taken aback to learn that many of the places that the children claimed were too small for adults (including myself) to access. Additionally, while the children happily showed me their places, they never invited me to enter their spaces. Most of the children were quite agile in their ability to fit into small spaces. Several showed me how they liked to hide inside closets with builtin shelves and tight spaces. Emily crawled through the small space under the dining room chairs to show me her special place under the table. One of John's favorite special places was in the tiny space under his brother's crib. Sara liked to climb on the back of a couch and hide behind the curtains. Lisa and Tesa both liked to play in their closets, and Robert's attempt to crawl under his bed suggested that he also had an interest in small places.

In the open-ended environment of the forest, it was challenging for the children to tuck away into small places. Instead the children sought private places where they could play undisturbed by adults and other children. This segment from Heather's sensory tour, revealed how the presence of a teacher nearby stalled the children's play:

Heather and Priscilla were making "tea" in the forest. Heather disclosed to Priscilla that she was thirsty and Heather dared her to ask the teacher for a drink. Noticing a teacher nearby, Priscilla's eyes got big and they paused from their play.

"Hugh! Tell the teacher..." Priscilla dared Heather.

"Hugh...tell the teacher..." Heather repeated.

The two girls look at each other. The teacher walks towards the girls who remain still and quiet. Heather rubs a leaf against the tree. They look back towards the teacher who pauses to converse with another group of children. Seeing that the teacher is once again occupied, the girls resume their play. 
In this case, the presence of a teacher interrupted the children's achievement of spatial autonomy. The children stalled in their play, which suggests a loss of comfort and independence in their exercise of agency in their environment.

While on the one hand, the presence of adults disrupts the children's achievement of spatial autonomy. On the other hand, the findings reveal how parents also positively influenced children's enactment of spatial autonomy. In the special place study, some parents purposively designed special places for their children to play in. John's mother placed fake food and play items in a kitchen cupboard for John to pretend to cook. She also created a special drawer for John to store his tiny treasures. Robert's mother positioned books in the cubby at the head of his bed, attracting Robert to this place to read.

Family and parental influence on children's place connections was also presumed in the forest study. From the very first day, some children were reluctant to venture into the forest to play, while others were quite confident. Likely, some had had more opportunities for free play in the forest with their families than others. While parents or caregivers should not initiate children's enactment of spatial autonomy, they can certainly provide a foundation of comfort and security, which influences children's confidence in venturing into their environment (Green, Kalvaitis, \& Worster, 2016).

\section{Furthering Theory on Children's Spatial Autonomy}

So how can these findings be taken together to further theory on young children's spatial autonomy? Three themes emerged across the findings of the two studies including children's enactment of independence, their negotiation of agency within adult structure and regulations, and multiple facets of children's relational dynamics. These will be described in further detail in the sections that follow.

\section{Spatial autonomy as an expression of children's independence}

Spatial autonomy is an expression of children's independence, which is explicitly linked to the social-cultural elements of particular settings. While past studies have examined how children's spatial autonomy is enacted through outdoor fort-making in middle childhood (Kjørholt, 2008; Kylin, 2003; Sobel, 2002), and as a negotiation between work and play in rural non-Western contexts such as in Bolivia (Punch, 2002), this paper specifi- 
cally examines how young preschool children from the United States express their spatial autonomy inside their home environments and outside in a forest setting. Children's home environments are highly controlled and regulated by their parents. As such, inside their homes, children achieved spatial autonomy by claiming small (micro) places within their environments. Spaces such as behind a couch, in a cupboard, under a crib or bed provided children with independence from adult authority where they could exercise control over their environment. Furthermore, by claiming these microspaces children exercised their freedom to play exclusively with others, hide from adults and siblings, and/or be alone. In these spaces, children brought with them particular play objects, including toys, stuffed animals, and dolls. Children's places were often located in common areas (e.g. living rooms and kitchens) where they could observe family happenings yet maintain a sense of privacy. However, children also preferred personalized spaces located in their bedrooms, including in and under their beds, beneath blankets, and amongst their favorite toys.

Independence, as a primary construct of children's spatial autonomy, was also gained in the forest environment. However, unlike the home environment, the forest setting appeared less restrictive and controlled by adults. The places that children sought were not necessarily hidden nor were they small. Rather, children achieved spatial autonomy through their imagination by transforming natural features into places and props for their symbolic play. Children ventured to high places for a heightened view of the world, towering over other children and adults. These places made them feel strong and the feat of ascending a tree seemed to both be driven by and inform a child's sense of self-confidence. Children imagined the forest into magical places for princesses and superheroes, doing battle with sticks that were transformed into bad guys and partaking in leaves and flower petals, which symbolized delicious treats. Through the achievement of spatial autonomy children achieved some level of control over their environments and the objects and spaces within them. This, in turn, builds and strengthens their confidence, independence, and self-identity (Laufer \& Wolf, 1977).

\section{Children's spatial autonomy as influenced and negotiated with adults}

While children's spatial autonomy is characterized by their exercise of independence, it is also both influenced and negotiated within adult boundaries, rules, and expectations. This idea is not new to the literature. Previous research has described how children negotiate their spatial autonomy in relation to the social and cultural expectations placed on them by more 
powerful adults (Punch, 2002). However, the findings from the research presented in this paper extend this understanding by examining how spatial negotiation is enacted among young children. First, the findings show that through the act of hiding in their home settings children are able to adjust and bend adult rules, asserting their power and control in a setting that is highly structured by adults. Second, by claiming high places (e.g., scaling up trees in the forest) some children also exercised a level of autonomy and control over their environment by elevating themselves above adult authority figures and their peers. Although adults asserted the rule that the children must be in visual range of an adult, the high places provided the children with a space out of reach from adult teachers.

Finally, as Benwell (2013) points out, "the imposition of adult structure and surveillance on childhood should not be automatically perceived as negative" (p. 28). Adults can positively influence children's autonomous choices and spatial preferences. The young children in the special place study indicated their preference for reading nooks and crannies purposively designed by their parents. Children expressed their desire to snuggle with their stuffed animals and read books on their bed - a comfortable space, which one could argue played a positive role in their identity formation. Additionally, the preschool children's level of comfort at engaging in their forest environment was most likely influenced by previous familial exposure, although this was not explicitly accounted for in the data collected. All in all, the examples in this paper extend understanding of how young children negotiate their spatial autonomy amidst adult-imposed structures and regulations. This paper shows that it is through the just-out-of-reach places claimed by children, although characterized a bit differently in the two settings, that children gain a sense of independence and control.

\section{Children's spatial autonomy is relational}

Finally, children's spatial autonomy is relational; however, different social and phenomenological relations inform children's spatial autonomy in their home and forest settings. In the home environment, human-to-human relations were expressed primarily between children and parents, through spatial negotiations, as described above. Additionally, spatial autonomy was also negotiated between siblings in the home environment, for example, in Sara and Caleb's performance of hide and seek in their home. Caleb followed Sara's lead in hiding, when Sara slid under her bed Caleb mimicked her, sliding under his. Caleb was younger than Sara and, perhaps because of this, Caleb submitted to Sara's charge. Whereas, in the forest study the 
children's spatial autonomy was heavily influenced by peer culture and to a lesser extent the teachers' rules and expectations. Groups of peers identified forts, castles, and houses and negotiated what and how they related to those spaces. Children scaled up trees, not only because they wanted to, but also because adult teachers allowed them to. The children quieted their play when they were threatened by interruption from teachers or worried about not adhering to teachers' expectations. Finally, it should be noted that the relational dynamic of the children's spatial autonomy in both environments was signified by the roles they chose to take on during play and how they symbolically related to other human and non-human elements in their environment. These roles provided the children with the autonomy to transform places and objects, relating to others in a way that best suited their individuality.

\section{Conclusion}

Spatial autonomy is an important theoretical construct in the study of children's geographies and other related disciplines, as it signifies the importance of children's exertion of agency in various spatial contexts. Yet although it has been commonly referred to in the literature (Bromley \& Mackie, 2009; Freeman, 2010; Lehman-Frisch, Authier \& Dufaux, 2012; Punch, 2002; Tomanović \& Petrović, 2010; Travlou, Owens, Thompson \& Maxwell, 2008; Wilson, Houmøller \& Bernays, 2012), a theoretical framing for the construct has not been fully developed. This paper provides an important contribution to the literature by specifying what spatial autonomy can include, mean, and how it is enacted by young children (ages 3-6 years) in their home and forest environments.

While the findings presented in this article certainly provide insight as to how spatial autonomy is achieved in the lives of young children, it is important to point out that both studies were situated within Western middle class culture. Emerging findings from a more recent study of Alaskan Native children growing up in a rural setting (Green, 2017) suggests that there may be some differences in the way culture and geography influence children's enactment of spatial autonomy. For example, fishing, berry picking, and participating in other subsistence-based activities occupy much of children's outdoor time in nature in rural Alaskan Indigenous settings (Green, 2017). The findings presented in this article emphasize spatial autonomy as a construct enacted through recreational activities (e.g., playing and hiding). Future studies could examine children's spatial autonomy in collectivist cultures, particularly in cultures accustomed to a subsistence 
lifestyle. With that said, in this conceptualization of spatial autonomy as a self-directed space where one might develop a sense of individuality and self-competency, there is no reason to assume that this should be accomplished independently. Rather spatial autonomy should be recognized as a positive construct that can be accomplished alone or collectively with others, and as the findings show, the achievement of spatial autonomy boasts a child's emerging sense of self, their self-confidence, and the relations in which they forge with place and their environments.

\section{Acknowledgements}

Special thanks to the children, undergraduate research assistants, teachers, and community partner for helping to make the projects successful. Funding for the forest research project was provided by the Undergraduate Research and Scholarly Activity (URSA) funds at the University of Alaska Fairbanks as well as support from Alaska EPSCoR NSF award \#OIA1208927 and the State of Alaska.

\section{References}

Autonomy. (2018). In Merriam-Webster dictionary online. Retrieved from https:// www.merriam-webster.com/dictionary/autonomy

Benwell, M. C. (2013). Rethinking conceptualisations of adult-imposed restriction and children's experiences of autonomy in outdoor space. Children's Geographies, 11(1), 28-43.

Bromley, R. F., \& Mackie, P. K. (2009). Child experiences as street traders in Peru: Contributing to a reappraisal for working children. Children's Geographies, 7(2), 141-158.

Chawla, L. (1992). Childhood place attachments. In I. Altman, \& S. Low (Eds.), Place attachment (pp.63-86). New York: Plenum.

Cobb, E. (1977). The ecology of imagination in childhood. New York: Columbia University.

Corsaro, W. M. (2015). The sociology of childhood (4th $e d$.$) . Thousand Oaks, CA: Sage.$ Freeman, C. (2010). Children's neighbourhoods, social centres to 'terra incognita'. Children's Geographies, 8(2), 157-176.

Green, C. (2011). A place of my own: Exploring preschool children's special places in the home environment. Children, Youth, and Environment, 21(2), 118-144.

Green, C. (2013). A sense of autonomy in young children's special places. International Journal of Early Childhood Environmental Education, 1(1), 8-33.

Green, C. (2014). "Because we like to": Young children's experiences hiding in their home environment. Early Childhood Education Journal, 43(4), 327-336.

Green, C. (2015a). "Because we like to": Young children's experiences hiding in their special places. Early Childhood Education Journal, 43(4), 327-336. 
Green, C. (2015b). Towards young children as active researchers: A critical review of the methodologies and methods in early childhood environmental education research. Journal of Environmental Education, 46(4), 207-229.

Green, C. (2016a). Sensory tours as a method for engaging children as active researchers: Exploring the use of wearable cameras in early childhood research. International Journal of Early Childhood, 48(3), 277-294.

Green, C. (2016b). Monsters or good guys: The mediating role of emotions in transforming young children's encounters with nature. Canadian Journal of Environmental Education, 21, 125-144.

Green, C. (2017a). Four methods to engage young children as environmental education researchers. International Journal of Early Childhood Environmental Education, 5, 6-19. Retrieved from https://cdn.naaee.org/sites/default/files/eepro/resource/ files/ijecee_51.pdf

Green, C. (2017b). Children environmental identity development in an Alaska Native rural context. International Journal of Early Childhood, 49(3), 303-319.

Green, C., Kalvaitis, D., \& Worster, A. (2016). Recontextualizing psychosocial development in young children: A model of environmental identity development. Environmental Education Research, 22(7), 1025-1048.

Hart, R. (1979). Children's experience of place. New York: Irvington.

James, A. (2000). Embodied beings: Understanding the self and the body in childhood. In A. Prout, \& J. Campling (Eds.), The body, childhood and society (pp. 19-37). New York, NY: St. Martin's Press.

James, A. (2009). Agency. In J. Qvortrup, W. A. Corsaro, \& M. S. Honig (Eds.), The Palgrave handbook of childhood studies (pp. 34-45). New York, NY: Palgrave MacMillan.

Kjørholt, A. (2003). Creating a place to belong: Girls' and boys' hut-building as a site for understanding discourses on childhood and generational relations in a Norwegian community. Children's Geographies, 1(1), 261-279.

Kylin, M. (2003). Children's dens. Children, Youth and Environments, 13(1). Retrieved From http://www.colorado.edu/journals/cye/13_1/Vol13_1Articles/CYE_CurrentIssue_Article_Dens_Kylin.htm.

Laufer, R., \& Wolfe, M. (1977). Privacy as a concept and a social issue: A multidimensional developmental theory. Journal of Social Sciences, 33(3), 22-41.

Lehman-Frisch, S., Authier, J., \& Dufaux, F. (2012). 'Draw me your neighbourhood': A gentrified Paris neighbourhood through its children's eyes. Children's Geographies, 10(1), 17-34.

Lowry, P. (1993). Privacy in the preschool environment: Gender differences in reaction to crowding. Children's Environments 10(2), 46-61.

Proshansky, H.M., \& Fabian, A. K. (1987). The development of place identity in the child. In C.S. Weinstein, \& T.G. David, (Eds.), Spaces for children: The built environment and child development (pp.21-40). New York: Plenum Press.

Punch, S. (2002). Negotiating autonomy: Childhoods in rural Bolivia. Conceptualising child-adult relations (pp. 37-50). Routledge.

Schwandt, T. A. (2015). The Sage dictionary of qualitative inquiry (4th ed.). Thousand Oaks, CA: Sage.

Seamon, D. (2014). Place attachment and phenomenology: The synergistic dyna- 
mism of place. In L. C. Manzo, \& P. Devine-Wright (Eds.), Place attachment: Advances in theory, methods and applications (pp. 11-22.). New York, NY: Routledge. Smilansky, S., \& Shefatya, L. (1990). Sociodramatic play: Its relevance to behavior and achievement in school. In E. Klugman, \& S. Smilansky (Eds.), Children's play and learning: Perspectives and policy implications (pp. 18-42). New York: Teachers College Press.

Sobel, D. (2002). Children's special places: Exploring the role of forts dens, and bush homes in middle childhood. Detroit: Wayne State University.

Spatial. (2018). In Merriam-Webster Dictionary online. Retrieved from https://www. merriam-webster.com/dictionary/spatial

Tomanović, S., \& Petrović, M. (2010). Children's and parents' perspectives on risks and safety in three Belgrade neighbourhoods. Children's Geographies, 8(2), 141-156. Travlou, P., Owens, P. E., Thompson, C. W., \& Maxwell, L. (2008). Place mapping with teenagers: Locating their territories and documenting their experience of the public realm. Children's Geographies, 6(3), 309-326.

Valentine, G. (2004). Public space and the culture of childhood. New York, NY: Routledge.

Wilson, S., Houmøller, K., \& Bernays, S. (2012). 'Home, and not some house': Young people's sensory construction of family relationships in domestic spaces. Children's Geographies, 10(1), 95-107.

\section{Author:}

Carie J. Green, Assoc. Professor

University of Alaska Fairbanks

School of Education

P. O. Box 756480

Fairbanks

AK USA 99775

E-mail: cjgreen2@alaska.edu 